\title{
The Cholinergic System in Schizophrenia Reconsidered: Anticholinergic Modulation of Sleep and Symptom Profiles
}

\author{
Rajiv Tandon, M.D., Stephan F. Taylor, M.D., John R. DeQuardo, M.D., Alan Eiser, Ph.D., \\ Michael D. Jibson, M.D., Ph.D., and Mona Goldman, Ph.D.
}

The role of the cholinergic system in schizophrenia remains controversial. A series of investigations are reviewed that describe the effects of pharmacological manipulation of the cholinergic system on schizophrenia symptomatology and whether putative measures of the cholinergic system are altered in schizophrenia. The effects of biperiden (an anticholinergic agent) on positive and negative symptoms of schizophrenia and on rapid eye movement (REM) latency and other sleep measures were assessed. Biperiden produced a significant increase in positive symptoms and a decrease in negative symptoms. REM latency was significantly shorter in schizophrenic patients and increased in both groups following biperiden. REM density decreased in a dose-dependent manner following biperiden in schizophrenic patients, but not in normal controls. The slope of REM density plotted against biperiden dose was inversely related to plasma homovanillic acid (HVA), an index of dopamine (DA) activity, in schizophrenic patients. These results further implicate the cholinergic system in schizophrenia pathophysiology and suggest a role for DAacetylcholine $(A C h)$ interactions in the production of sleep abnormalities and expression of positive and negative symptoms in schizophrenia.

[Neuropsychopharmacology 22:S189-S202, 1999] (c) 1999 American College of Neureopsychopharmacology. Published by Elsevier Science Inc.
KEY WORDS: Schizophrenia; Receptors, Cholinergic; Receptors, muscarinic; Parasympathetic nervous system; Sleep, REM; Symptoms, positive; Symptoms, negative

The dopamine (DA) hypothesis has dominated biochemical and pharmacological research on schizophrenia for about two decades. Although pharmacological data implicate increased DA activity in the pathogenesis of positive symptoms of schizophrenia, there is minimal association with negative symptoms (Crow 1980; Andreasen and Olsen 1982; Angrist et al. 1980). The

From the Schizophrenia Program, University of Michigan Medical Center, Ann Arbor, Michigan.

Address correspondence to: Rajiv Tandon, M.D., Professor, Schizophrenia Program, University of Michigan Medical Center, 1500 E. Medical Center Drive, Ann Arbor, MI 48109-0120. Tel.: 734936-4960. Fax: 734-936-9983. E-mail: rtandon@umich.edu

Received July 9, 1999; accepted August 2, 1999. poorly elucidated pathogenesis of negative symptoms and the unique properties of the atypical antipsychotic clozapine (Jibson and Tandon 1998) have encouraged a reappraisal of the role of the DA system in schizophrenia. Newer approaches to evaluating neurochemical abnormalities in schizophrenia include consideration of other neurotransmitter systems. Models of DA-serotonin (Meltzer 1989), DA-glutamate (Carlsson and Carlsson 1990), DA-acetylcholine (Tandon and Greden 1989), and DA-norepinephrine (van Kammen et al. 1990) interactions have been proposed. Although these models still accord DA a significant role in schizophrenia pathophysiology, they suggest that altered balance between DA and one (or more) of these other neurotransmitter systems may be the principal neurochemical abnormality related to the production of schizophrenic symptoms. 
Some of the earliest pharmacological treatments for schizophrenia included cholinergic agents (Cohen et al. 1944; Collard et al. 1946; Pfeiffer and Jenney 1957), and in the 1970s, several investigators suggested that cholinergic activity may be reduced in schizophrenia (Friedhoff and Alpert 1973; Janowsky et al. 1973; Davis et al. 1975; Singh and Kay 1979). There was no direct evidence of altered cholinergic functioning in schizophrenic patients, however, and pharmacological trials with cholinergic agents were generally ineffective (Rowntree et al. 1950; Gerlach et al. 1977; Davis and Berger 1978). With few exceptions (Johnstone et al. 1983; Singh et al. 1987), cholinergic mechanisms were increasingly considered irrelevant to the pathophysiology of schizophrenia and discussed predominantly with reference to the treatment of undesirable extrapyramidal side effects of neuroleptics (Richelson 1984). Indirect evidence from several lines of research, however, suggests that the cholinergic system may differentially influence positive and negative symptoms in schizophrenia (Tandon and Greden 1989).
We and others have been conducting various studies to evaluate the role of the cholinergic system in schizophrenia, based on a primary hypothesis that DA-acetylcholine (ACh) interactions are of central importance in the production of positive and negative symptoms of schizophrenia (Tandon and Greden 1989; Tandon and Greden 1991). Based on available data and on observations of the course of positive and negative symptoms during the acute phase of the illness (Donlon and Blacker 1973; Docherty et al. 1978; Tandon et al. 1990a), we posited a role for disruption in DA-ACh balance in the expression of positive and negative schizophrenic symptoms (Tandon and Greden 1989). We proposed that: (1) disruption of DA-ACh balance is of central importance in the expression of schizophrenic psychopathology; (2) increasing dopaminergic activity in the psychotic phase of the illness is accompanied by increased cholinergic activity in a homeostatic response to restore balance; (3) the cholinergic system exerts a damping effect on the emergence of positive symptoms associated
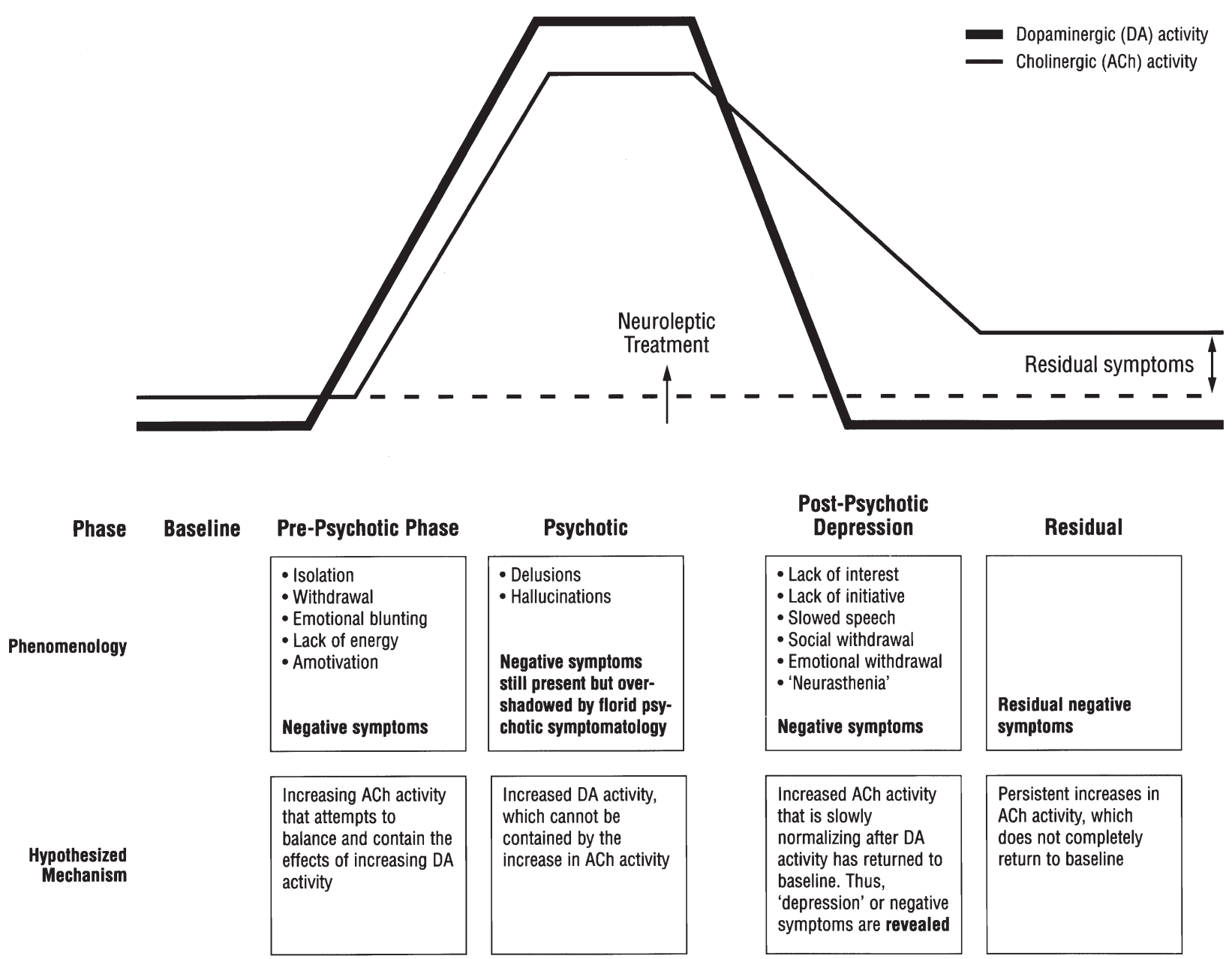

Psychotic

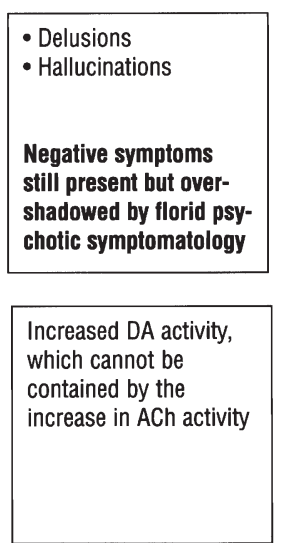

Post-Psychotic Depression

\begin{tabular}{|c|}
\hline $\begin{array}{l}\text { - Lack of interest } \\
\text { - Lack of initiative } \\
\text { - Slowed speech } \\
\text { - Social withdrawal } \\
\text { - Emotional withdrawal } \\
\text { - 'Neurasthenia' } \\
\text { Negative symptoms }\end{array}$ \\
\hline $\begin{array}{l}\text { Increased ACh activity } \\
\text { that is slowly } \\
\text { normalizing after DA } \\
\text { activity has returned to } \\
\text { baseline. Thus, } \\
\text { 'depression' or negative } \\
\text { symptoms are revealed }\end{array}$ \\
\hline
\end{tabular}

Residual

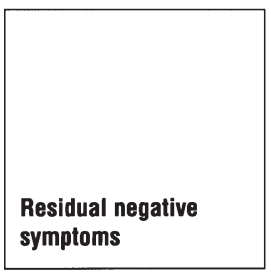

Persistent increases in ACh activity, which does not completely return to baseline

Figure 1. Dopaminergic-cholinergic interactions and the phenomenology of an acute psychotic episode (adapted and modified from Tandon and Greden 1989). 
with dopaminergic hyperactivity; and (4) this compensatory increase in cholinergic activity is, in turn, accompanied by an intensification of negative symptoms during the acute phase of the illness (Figure 1). Further testing of this model has begun to determine whether pharmacological manipulation of the cholinergic system affects schizophrenic symptomatology and if putative indices of the cholinergic system are altered in schizophrenia. In this article, we review preliminary findings that provided the framework for the present series of studies evaluating the effect of anticholinergic modulation on symptomatology and polysomnographic measures in medication-free schizophrenic patients.

\section{PRELIMINARY INVESTIGATIONS}

\section{Effects of Pharmacological Manipulation of the Cholinergic System}

Behavioral Effects of Physostigmine in Normal Controls: A Model for Negative Symptoms. Intravenous infusion of physostigmine, a centrally active anticholinesterase agent, leads to a behavioral syndrome in normal subjects that is characterized by decreased and monotonous speech, slowed thoughts, expressionless faces, apathy, emotional withdrawal, and decreased energy (Janowsky et al. 1972; Davis et al. 1976; Risch et al. 1981). This clinical profile, previously proposed as a model for depression, is strikingly similar to the negative schizophrenic syndrome. In a study of the effects of intravenous physostigmine infusion in seven normal volunteers (Tandon et al. 1993), observer ratings and self-description revealed significant withdrawal, apathy, alogia, lethargy, slowed thoughts, diminished affective responsivity, and reduced hedonic capacity. This symptom profile was consistent with the results of other studies on the effects of cholinergic agents in schizophrenic patients, which consistently documented an exacerbation of negative symptoms in terms of an "inhibitory effect" (Janowsky et al. 1973; Rowntree et al. 1950; Modestin et al. 1973).

Treatment of Negative Symptoms of Schizophrenia with Trihexyphenidyl. The beneficial effects of antiparkinsonian medication have been noted in a sizable proportion of schizophrenic patients; withdrawal of these agents leads to subjective distress, social withdrawal, and "depressive symptomatology" (Rifkin et al. 1978; Manos et al. 1981). Furthermore, anticholinergic "drug abuse" is relatively frequent in schizophrenia, with patients describing mood-elevating, energizing, and socializing effects of these agents (Fisch 1987; Wells et al. 1989). In an 8-week open-label pilot study on the effects of trihexyphenidyl $10 \mathrm{mg}$ daily on negative symptoms in five neuroleptic-treated chronic schizophrenic patients with predominantly negative symptoms (Tan- don et al. 1988), a significant reduction in the severity of negative symptoms was achieved, as assessed by the Scale for the Assessment of Negative Symptoms (SANS) (Andreasen 1983). Substantial improvement was observed in four of five patients, mainly in the areas of affective flattening, anhedonia-asociality, and avolition-apathy. These changes were noted both 4 and 8 weeks after initiating trihexyphenidyl treatment. Two other studies subsequently documented a similar improvement in "secondary" negative symptoms in chronic schizophrenic patients following anticholinergic treatment (Fayen et al. 1988; Sandyk and Kay 1990).

Because patients in the above study were receiving neuroleptic drugs, it is possible to ascribe the beneficial effects of trihexyphenidyl on negative symptoms to relief of akinesia (Rifkin et al. 1978), despite the apparent absence of extrapyramidal side effects. Consequently, we studied the effects of anticholinergic modulation on schizophrenic symptoms in drug-free patients. Some earlier studies had indicated that anticholinergics may antagonize the therapeutic effects of neuroleptics on positive symptoms (Singh and Kay 1979; Johnstone et al. 1983; Singh et al. 1987; Haase 1965; Johnstone et al. 1988; Chouinard et al. 1987), but controlled studies on the effects of anticholinergic drugs in medication-free schizophrenic patients were lacking.

We studied the effects of 2 days of treatment with biperiden, a relatively specific $\mathrm{M}_{1}$ antimuscarinic/anticholinergic agent, on positive and negative symptoms in 15 medication-free (minimum 2 weeks) schizophrenic patients (Tandon et al. 1990b). In this study, patients received 4-mg biperiden on night 1 , two doses of 4-mg biperiden the next day, and a 4-mg biperiden dose the morning of day 3 . Two nurse-clinicians, who were blinded to patients' treatment status and study rationale, independently rated patients on the 18-item Brief Psychiatric Rating Scale (BPRS) (Overall and Gorham 1962). Results showed a significant increase $(p<.01)$ in positive symptom severity following biperiden; mean positive symptom cluster scores were $12.8 \pm 3.6$ and $15.7 \pm 4.4$ at baseline and after biperiden treatment, respectively. In addition, there was a trend toward a decrease in negative symptoms, with mean negative symptom cluster scores of $9.0 \pm 3.7$ and $7.9 \pm$ 3.0 at baseline and after biperiden treatment, respectively. These findings were confirmed in a larger sample of 40 drug-free patients with schizophrenia (Tandon et al. 1992a). In the second study, biperiden produced a significant increase in positive symptoms $(p<.001)$ and a significant reduction in negative symptoms $(p<.01)$. These data indicate that modulation of the cholinergic neurotransmitter system affects positive and negative symptoms and suggest that cholinergic and anticholinergic agents should be studied in further controlled clinical trials for the treatment of positive and negative symptoms of schizophrenia, respectively. 


\section{In Vivo Measurement of Central Cholinergic Activity}

Although positron emission tomography (PET) and single-photon emission computed tomography (SPECT) may make in vivo regional quantitative assessments of cholinergic activity possible in the future, these techniques are not yet adequately developed. Cerebrospinal fluid or plasma levels of $\mathrm{ACh}$, choline (precursor of $\mathrm{ACh}$ ), or enzymes involved in ACh synthesis and destruction are of limited value (Schuberth and Jenden 1975; Sitaram and Gillin 1980), because of the lack of strong association with other indices of central cholinergic function. Polysomnographic measures (including rapid eye movement [REM] latency) and cortisol response to the dexamethasone suppression test (DST) are valuable indices of central cholinergic function (Sitaram and Gillin 1980; Gillin et al. 1978; Carroll et al. 1980). Although these are indirect measures, they are quantifiable, reliably measurable, and temporally linked to changes in cholinergic status. Therefore, they represent a reasonable starting point for exploring the question of whether biological markers of central cholinergic activity are altered in schizophrenia.

DST and Symptoms of Schizophrenia. Cholinergic stimulation increases hypothalamic-pituitary-adrenal axis activity, which results in DST nonsuppression (Carroll et al. 1980; Janowsky et al. 1986). To assess rates of DST nonsuppression in schizophrenia, we conducted a 1-mg DST in 44 schizophrenic inpatients at drug-free baseline and approximately 4 weeks after neuroleptic treatment (Tandon et al. 1991a). Patients were rated on positive, negative, and depressive symptoms at both timepoints. Thirty-nine percent of the patients were DST nonsuppressors at baseline, and $14 \%$ were nonsuppressors after 4 weeks of neuroleptic treatment. A meta-analysis of all published 1-mg DST studies in schizophrenia revealed comparable nonsuppression rates: $36 \%$ in the drug-free state and $20 \%$ in the medicated state (Tandon et al. 1991a). Postdexamethasone cortisol levels were significantly correlated with negative symptom severity but unrelated to positive or depressive symptoms. Although alternative explanations are possible, these data are consistent with cholinergic hyperactivity in schizophrenia, which may increase negative symptoms.

Electroencephalographic Sleep Abnormalities in Schizophrenia: Relationship to Symptoms and Prior Neuroleptic Treatment. To investigate possible sleep EEG abnormalities in schizophrenia, we recorded sleep EEG in 20 drug-naive schizophrenic patients, 20 drug-free but previously medicated schizophrenic patients, and 15 normal controls (Tandon et al. 1992b). We observed that both drug-naive and previously medicated schizophrenic patients had significantly greater impairment of sleep continuity and shorter REM latency when compared to controls. We also found REM latency to be inversely correlated with the severity of negative symptoms, but unrelated to depressive symptoms. We confirmed these findings in another nonoverlapping sample of 20 antipsychotic-naive and 20 drug-free previously medicated schizophrenic patients and 20 healthy controls (Maixner et al. 1996). Considering known cholinergic effects on REM latency and other sleep measures (Sitaram et al. 1978; Gillin and Sitaram 1984), these data are consistent with the hypothesis of increased cholinergic activity in schizophrenia and its implication in the production of negative symptoms. In related studies (Taylor et al. 1991; Maixner et al. 1998; Tandon 1997), we observed that polysomnographic measures partially normalized following antipsychotic treatment (with neuroleptics, clozapine, and risperidone). Assuming that increased cholinergic activity partly underlies polysomnographic abnormalities in schizophrenia at drug-free baseline, these data may indicate a trend for increased cholinergic activity to partially normalize with neuroleptic therapy (Figure 1) (Tandon and Greden 1989; Tandon et al. 1990a).

Effects of Biperiden on Polysomnographic Measures in Schizophrenia. Both DST response and polysomnographic measures were found to be abnormal and altered in a manner consistent with increased cholinergic activity in schizophrenia. Furthermore, a strong association between these measures has been observed in schizophrenic patients (Tandon et al. 1996). Because multiple noncholinergic mechanisms influence both DST response and polysomnographic results, however, these data are suggestive at best and do not lend themselves to any definitive interpretation. In the hope of determining the cholinergic contribution to these abnormalities and providing a more refined index of central cholinergic function than simple baseline parameters, we turned our attention to studying the effects of cholinergic/anticholinergic modulation using polysomnography (Sitaram and Gillin 1980; Gillin and Sitaram 1984).

There have been several studies on the effects of cholinergic/anticholinergic challenge on polysomnographic measures in other psychiatric disorders (Berger et al. 1989; Poland et al. 1997), but this strategy had not been employed in schizophrenia. In an exploratory study (Tandon et al. 1991b), we compared the effects of biperiden on sleep measures in 12 schizophrenic patients and 10 normal controls. We chose an anticholinergic rather than cholinergic challenge strategy, because our model postulates increased cholinergic activity in schizophrenia, and we were concerned about a possible ceiling effect if we employed a cholinomimetic. In addition, cholinergic activation is associated with EEG desynchronization and arousal from sleep, and no oral 
cholinergic agent with an adequate half-life was available. We selected biperiden as the anticholinergic agent for the following reasons: (1) it is selective for $\mathrm{M}_{1}$ receptors, causes fewer peripheral anticholinergic side effects, and is better tolerated by subjects (Syvalahti et al. 1987; Eltze and Figala 1988; Avissar and Schreiber 1989); (2) its blockade of catecholamine reuptake is less pronounced than that of other oral anticholinergics (Horn et al. 1971; Modell et al. 1989); and (3) its pharmacokinetics make it a good choice for studying cholinergic mechanisms in sleep (Hollmann et al. 1984; Grimaldi et al. 1986; Gillin et al. 1991). There were no other reports on the effects of biperiden on sleep measures when we started our study, and the doses of 6 and 10 $\mathrm{mg}$ that were selected were somewhat higher than those used in two studies that were published subsequently (Gillin et al. 1991; Salin-Pascual et al. 1991). Compared to other studies of biperiden on sleep measures, we found that biperiden caused a smaller increase in REM latency in schizophrenic patients than in normal controls, suggesting that muscarinic activity is increased in schizophrenia (Tandon et al. 1991b).

Based on our previous findings with biperiden, we designed two studies: a symptom study to compare the effects of biperiden and glycopyrrolate on positive and negative symptoms of schizophrenia in drug-free patients and a sleep EEG study to compare the effects of 6 and $10 \mathrm{mg}$ of biperiden on polysomnographic measures in drug-free schizophrenic patients and normal controls.

\section{STUDY DESIGN}

\section{Symptom Study}

Several potential biases and confounding factors of earlier studies (Tandon et al 1990b, 1992a) were eliminated. We employed a double-blind, placebo-crossover design, randomizing the order of active drug versus placebo in drug-free schizophrenic patients, and compared the effects of biperiden with an active placebo, glycopyrrolate (which has peripheral anticholinergic activity, but is devoid of central anticholinergic activity). We hypothesized that biperiden, but not glycopyrrolate, would increase positive symptoms and decrease negative symptoms.

\section{Sleep EEG Study}

Our previous study of the effects of biperiden on polysomnographic measures lacked systematic dosing and included relatively few patients (Tandon et al. 1991b). The present study addressed these design issues and evaluated the dose-response relationship of the effects of biperiden on sleep measures. We assessed the effects of two doses of biperiden on polysomnographic mea- sures and plasma homovanillic acid (HVA) in schizophrenic patients and normal controls. HVA is one of the primary metabolites of dopamine, and levels of HVA are often used as an index of the functional activity of dopaminergic neurons in the brain. In the present study, plasma HVA was measured as an index of dopaminergic activity to directly assess the dopaminergic component of the DA-ACh interactions. We hypothesized that schizophrenic patients would exhibit shorter REM latency, reflecting increased cholinergic activity. In addition, schizophrenic patients would exhibit a greater reduction in REM density to biperiden than normal controls, reflecting DA-ACh interactions. We also hypothesized that a significant inverse correlation would be demonstrated between the slope of REM density plotted against biperiden dose and plasma HVA level; that is, when the increased ACh activity in schizophrenic patients was blocked by biperiden, there would be a greater reduction in REM density because of the increased DA activity reflected by higher HVA levels.

\section{METHODS}

\section{Subjects}

Twenty patients with schizophrenia were included in the symptom study; 24 different schizophrenic patients and 20 normal controls were included in the sleep EEG study. All subjects were from 20 to 50 years of age, provided informed consent, were medication-free for at least 2 weeks, had no serious medical illnesses or major physiological disturbances, and did not abuse alcohol or other substances for at least the preceding 3 months. For participation in the sleep study, a primary sleep disorder was excluded by a sleep disorders questionnaire (Douglass et al. 1986) and a first-night full-montage recording. Patients were required to meet DSM-III-R (American Psychiatric Association 1987) and Research Diagnostic Criteria (RDC) (Spitzer et al. 1978) for schizophrenia and criterion A of DSM-III-R (presence of characteristic psychotic symptoms). Patients were excluded if they met criteria for any other Axis 1 or Axis 2 disorder or if they had received any depot neuroleptics in the 6 months preceding the study. Normal controls were individuals who were classified as "never mentally ill" by RDC criteria, with no prior or current treatment by a mental health professional, and all had a normal physical examination and screening tests, including drug screen and electrocardiogram (ECG).

\section{Diagnostic Evaluation Procedures}

A diagnosis was established and inclusion/exclusion criteria were applied using unstructured clinical interviews conducted by a faculty psychiatrist and a structured psychiatric interview using the Schedule for Af- 
fective Disorders and Schizophrenia (SADS) (Endicott and Spitzer 1978) for patients and SADS-Lifetime Version (L) (Spitzer and Endicott 1979) for normal controls, administered by a research nurse. A psychiatric social worker conducted a comprehensive family interview that focused on the patient's course of illness and obtained information from family members about the patient's history and clinical features. All previous records of comprehensive clinical and laboratory assessments were reviewed to screen for physical disorders, including a detailed review of systems, physical and neurological examination, chest radiographs, laboratory assessments, urinalysis, urine toxicology screens, and ECGs. The final diagnostic categorization was made at a research team consensus conference.

\section{Symptom Study: Effects of Biperiden on Positive and Negative Symptoms}

In this study, we compared the effects of biperiden versus glycopyrrolate on positive and negative symptoms in 20 drug-free schizophrenic patients. Biperiden was administered orally at a dose of $4 \mathrm{mg}$ twice daily and glycopyrrolate at a dose of $1 \mathrm{mg}$ twice daily. After a 2-week drug-free period, patients participated in a 12-day trial. Following the initial clinical assessment on day 1 , patients received no drug for 4 days. Starting on day 5 in the evening, following a second clinical assessment, subjects received one anticholinergic agent for 4 days (either biperiden or glycopyrrolate). Starting on day 9 in the evening, following a third clinical assessment, subjects were crossed over and received the other agent for 4 days until the morning of day 13, when they had their final clinical assessment. Patients who received biperiden from days 5 to 9 received glycopyrrolate from days 9 to 13; conversely, patients who received glycopyrrolate from days 5 to 9 received biperiden from days 9 to 13 . The order of biperiden versus glycopyrrolate was randomized, with an equal number of patients (10 in each group) receiving biperiden or glycopyrrolate first. Patients were rated on the BPRS (Overall and Gorham 1962) on day 1 (drugfree baseline 1), day 5 (drug-free baseline 2), day 9 (either glycopyrrolate or biperiden), and day 13 (either glycopyrrolate or biperiden) by a rater who was blind to treatment. Positive and negative symptoms were assessed by the BPRS "THOT" and "ANER" clusters, respectively (Angrist et al. 1980; Tandon et al. 1990a; Guy 1976; Hedlund and Vieweg 1980); items assessing motor retardation, blunted affect, and emotional withdrawal (rated 1 for "not present" to 7 for "severe") were summed to form the BPRS negative symptom cluster, and the BPRS items assessing conceptual disorganization, suspiciousness, hallucinatory behavior, and unusual thought content were summed as the BPRS positive symptom cluster. The severity of positive and negative symptoms at the four time points were compared by the repeated measures analysis of variance (ANOVA).

\section{Sleep EEG Study: Effects of Biperiden on Polysomnographic Measures in Schizophrenic Patients and Normal Controls}

All sleep recordings were carried out after a drug-free period of at least 2 weeks. On the first night of study, a full montage polysomnogram was recorded on all subjects; on nights 2 and 3, only sleep staging was performed. On night 3 , all subjects received either 6 or 10 $\mathrm{mg}$ of biperiden 30 minutes before bedtime. Sleep EEG was monitored in all subjects for three consecutive nights. Daytime naps were not permitted. Recordings were obtained from normal controls using outpatient recording rooms directly wired to the adjacent sleep laboratory control room. Schizophrenic inpatients were recorded from their own hospital beds, which were directly wired to the nearby sleep laboratory control room; this minimized the confounding effects associated with changing rooms and beds. All polygraph records were scored visually according to modified Rechtschaffen-Kales criteria (Rechtschaffen et al. 1968) by raters blind to diagnosis. Further details of the sleep methodology are available in a prior publication (Tandon et al. 1992b). The sleep EEG variables included sleep continuity, sleep architecture, and REM sleep indices. Sleep continuity indices were time spent asleep (TSA) or net sleep time, and sleep latency (SL), the time from the beginning of the recording until the onset of any of Stages 2, 3, 4, or REM sleep lasting at least 10 minutes. Sleep architecture indices were percentages of net sleep time (TSA) spent in the stages of slow-wave sleep $($ SWS $=$ Stage $3+4$ sleep $)$ and in REM sleep. REM sleep indices were REM sleep time (RT), REM activity (RA), which is an integrative measure of the frequency of rapid eye movements per minute of REM sleep, scored visually on an analog scale of 0 to 8, REM density (RA/RT), and corrected REM sleep latency (RLMA), defined as the time between sleep onset and the first REM period (of at least 3 minutes duration) minus intermittent wakefulness during that interval.

Blood samples for plasma HVA levels were obtained during the medication-free baseline period. Physical exercise, high-monoamine diets, alcohol, and caffeine were restricted for all subjects for at least 48 hours before the blood sampling. Blood samples were obtained between 9:00 and 10:00 AM. Plasma was separated by centrifugation and stored at $-80^{\circ} \mathrm{C}$ until analysis by high-performance liquid chromatography (HPLC).

Sleep measures in the two groups were compared by the three-way ANOVA; dose $(6 \mathrm{mg}$ and $10 \mathrm{mg}$ ) and diagnosis (schizophrenia and control) were the grouping factors, and baseline and biperiden sleep measures 
were the repeated measure. Sleep data were appropriately transformed (square root/log) to normalize the data before statistical analysis. The association between change in REM density following biperiden per mg of biperiden and plasma HVA was assessed by Pearson's product-moment correlation analysis.

\section{RESULTS}

\section{Symptom Study: Effects of Biperiden on Positive and Negative Symptoms}

The sample of 20 patients consisted of 12 males and 8 females, with a mean age of $29 \pm 8$ years, and a mean duration of illness of $7 \pm 5$ years. All patients completed the study. The effects of biperiden and glycopyrrolate on global severity (18-item BPRS total score), positive symptoms, and negative symptoms are summarized in Table 1. Global severity did not differ significantly across the four time points (two drug-free baselines, one glycopyrrolate, and one biperiden). Positive symptom scores following biperiden were significantly higher $(\mathrm{F}=6.3 ; p<.01)$, and negative symptom scores were significantly lower $(\mathrm{F}=4.7 ; p<.02)$ than corresponding measurements. Both biperiden and glycopyrrolate were well tolerated. Dryness of mouth and mild tachycardia were the only side effects; there was no difference in the frequency of these side effects during treatment with biperiden or glycopyrrolate.

Although there were no significant differences between mean positive and negative symptom scores at drug-free baseline and with glycopyrrolate, there was a trend toward a significant order effect, with mean glycopyrrolate positive symptom scores being lower than drug-free baseline scores in the group that received biperiden first $(n=10, p<.10)$. There was no such difference between positive symptom scores at drug-free baseline and with glycopyrrolate in the group that received glycopyrrolate first. This suggests that the observed decrease in positive symptoms at the glycopyrrolate phase in patients who received biperiden first may be attributable to a cholinergic rebound after withdrawal from biperiden.

\section{Sleep EEG Study: Effects of Biperiden on REM Sleep Measures in Schizophrenic Patients and Normal Controls}

Twenty-six normal controls and 26 drug-free schizophrenic patients constituted the initial study sample; 13 subjects in each group received $6 \mathrm{mg}$ of biperiden on night 3 , and the other 13 subjects in each group received $10 \mathrm{mg}$ of biperiden on night 3 . Six normal controls (three receiving $6 \mathrm{mg}$ biperiden and three receiving 10 mg biperiden), and two schizophrenic patients (one each receiving $6 \mathrm{mg}$ or $10 \mathrm{mg}$ biperiden) had very disrupted sleep and no scorable REM sleep on the biperiden night; because REM sleep measures were the principal dependent variable, these subjects were not included in the final data analysis. Thus, the final study sample consisted of 24 schizophrenic patients and 20 normal controls. The 24 schizophrenic patients, including 15 males and 9 females, had a mean age of $28 \pm 8$ years and a mean duration of illness of $7 \pm 6$ years. The sample of 20 normal controls was comparable in age and gender distribution, with a mean age of $27 \pm 7$ years and 13 males and 7 females. The first sleep night served as an adaptation procedure and to screen for a primary sleep disorder; data from nights 2 and 3 constituted the baseline and biperiden sleep measures, respectively.

At drug-free baseline, patients with schizophrenia demonstrated significantly disrupted sleep continuity (all measures) and shorter REM latency than normal controls (Table 2 and Figure 2). There was a significant disruption in sleep continuity measures in both groups following biperiden. Minutes of REM sleep, percentage of REM sleep, and REM activity decreased in both groups following biperiden in a dose-dependent manner. REM latency increased following biperiden in both groups in a dose-dependent manner. REM density did not differ between the schizophrenia and control groups at baseline; whereas, REM density decreased signifi-

Table 1. Positive and Negative Symptoms and Global Severity of Schizophrenia at Drug-Free Baseline, after Glycopyrrolate, and after Biperiden $(n=20)$

\begin{tabular}{lcccccc}
\hline & $\begin{array}{c}\text { Drug-Free } \\
\text { Baseline 1 (A) }\end{array}$ & $\begin{array}{c}\text { Drug-Free } \\
\text { Baseline 2 (B) }\end{array}$ & $\begin{array}{c}\text { Placebo Baseline } \\
\text { (Glycopyrrolate) (C) }\end{array}$ & $\begin{array}{c}\text { Biperiden } \\
\text { (D) }\end{array}$ & $\begin{array}{c}p \text { Value } \\
\text { Contrasts } \boldsymbol{p}<.01\end{array}$ & $\begin{array}{c}\text { Bonferroni Pairwise } \\
\text { Con }\end{array}$ \\
\hline $\begin{array}{c}\text { Positive symptoms } \\
\text { (BPRS “THOT") }\end{array}$ & $16.1 \pm 2.6$ & $16.1 \pm 3.0$ & $15.1 \pm 3.0$ & $18.9 \pm 3.3$ & $<.01$ & $\mathrm{AD}, \mathrm{BD}, \mathrm{CD}$ \\
$\begin{array}{c}\text { Negative symptoms } \\
\text { (BPRS “ANER") }\end{array}$ & $11.3 \pm 2.8$ & $11.6 \pm 2.7$ & $11.3 \pm 2.5$ & $9.2 \pm 2.2$ & $<.02$ & $\mathrm{AD}, \mathrm{BD}, \mathrm{CD}$ \\
$\begin{array}{c}\text { Global severity } \\
\text { (BPRS TOTAL) }\end{array}$ & $54.3 \pm 8.0$ & $54.7 \pm 9.8$ & $51.5 \pm 9.5$ & $54.9 \pm 10.2$ & $\mathrm{NS}$ & - \\
\hline
\end{tabular}

BPRS $=$ Brief Psychiatric Rating Scale. 
cantly following biperiden in both groups, and it declined to a significantly greater extent in the schizophrenia group (interaction between repeated measure and patient-control grouping) (see Figure 3 and Table 2). The mean \pm standard deviation plasma HVA level was $13.3 \pm 3.9 \mathrm{ng} / \mathrm{ml}$. There was a significant inverse correlation between change in REM density per $\mathrm{mg}$ of biperiden and plasma HVA level in the schizophrenic patients $(\mathrm{r}=-.64 ; p<.01)$ (Figure 4$)$; REM density per $\mathrm{mg}$ of biperiden decreased with increasing levels of plasma HVA.

\section{DISCUSSION}

In the first study, positive symptoms increased and negative symptoms decreased following biperiden, but not following glycopyrrolate. In addition, mean glycopyrrolate positive symptom scores were lower than drug-free baseline scores in the group that received biperiden first, suggesting that there may have been a rebound increase in cholinergic activity after withdrawal from biperiden. In the second study, REM latency was significantly shorter in the schizophrenic group than in the control group at baseline and increased in a dosedependent manner in both groups during treatment with biperiden. REM density did not differ between the two groups at baseline, and biperiden caused a dosedependent reduction in REM density in both groups, with a significantly greater rate of reduction in schizophrenic patients than in normal controls. The slope of change in REM density following biperiden was inversely correlated to plasma HVA level in schizophrenic patients. Several studies have demonstrated the utility of plasma HVA levels as a measure of DA activity in the study of schizophrenia (Pickar et al. 1990; Davila et al. 1988; Sumiyoshi et al. 1997). Because REM density is determined by the balance of cholinergic and catecholaminergic (in this case, dopaminergic) activity, our results suggest that the greater reduction in REM density (a measure of DA-ACh interactions) in schizophrenic patients following cholinergic blockade may be related to increased DA activity. Moreover, the cholinergic system may influence positive and negative symptoms and polysomnographic abnormalities in schizophrenia, and thus, cholinergic mechanisms might be considerably more important in schizophrenic pathophysiology than previously recognized.

\section{Cholinergic/Anticholinergic Modulation and Schizophrenic Symptoms}

Anticholinergics are commonly used in the treatment of extrapyramidal side effects, which frequently accompany neuroleptic treatment in schizophrenia. The effects of anticholinergic drugs on schizophrenia symptoms in patients who are being treated with neuroleptics, however, have not been demonstrated consistently. Most studies showing no adverse effects of anticholinergics on positive symptoms (Rifkin et al. 1978; Manos et al. 1981) were conducted in the chronic neurolepticstabilized phase of the illness; whereas, investigations documenting adverse effects of anticholinergic drugs on positive symptoms (Singh et al. 1987; Haase 1965; Johnstone et al. 1988; Chouinard et al. 1987; and, the present study) were conducted in the acute phase of the illness. This observation suggests that anticholinergics may have adverse effects on positive symptoms only in

Table 2. Effects of Biperiden on Sleep EEG Measures in Schizophrenic Patients and Normal Controls

\begin{tabular}{|c|c|c|c|c|c|c|}
\hline & \multicolumn{2}{|c|}{ Baseline } & \multicolumn{2}{|c|}{$6 \mathrm{mg}$ Biperiden } & \multicolumn{2}{|c|}{10 mg Biperiden } \\
\hline & $\begin{array}{l}\text { Normal } \\
(n=20)\end{array}$ & $\begin{array}{l}\text { Schizophrenia } \\
\quad(n=24)\end{array}$ & $\begin{array}{l}\text { Normal } \\
(n=10)\end{array}$ & $\begin{array}{l}\text { Schizophrenia } \\
\quad(n=12)\end{array}$ & $\begin{array}{l}\text { Normal } \\
(n=10)\end{array}$ & $\begin{array}{l}\text { Schizophrenia } \\
\quad(n=12)\end{array}$ \\
\hline \multicolumn{7}{|l|}{ Sleep continuity } \\
\hline Sleep latency & $15 \pm 3$ & $66 \pm 13^{a}$ & $67 \pm 40$ & $103 \pm 20$ & $82 \pm 38$ & $112 \pm 39$ \\
\hline Time spent asleep & $396 \pm 8$ & $326 \pm 13^{a}$ & $323 \pm 39$ & $288 \pm 20$ & $259 \pm 38$ & $254 \pm 30$ \\
\hline \multicolumn{7}{|l|}{ Sleep architecture } \\
\hline Slow-wave sleep (\%) & $12 \pm 2$ & $9 \pm 2$ & $20 \pm 3$ & $14 \pm 3$ & $15 \pm 3$ & $10 \pm 3$ \\
\hline $\operatorname{REM}(\%)$ & $22 \pm 3$ & $22 \pm 4$ & $16 \pm 4$ & $15 \pm 4$ & $13 \pm 4$ & $13 \pm 3$ \\
\hline \multicolumn{7}{|l|}{ REM Sleep Measures } \\
\hline REM latency & $93 \pm 9$ & $63 \pm 9^{b}$ & $136 \pm 24$ & $98 \pm 23^{c}$ & $147 \pm 26$ & $136 \pm 24$ \\
\hline REM activity & $84 \pm 8$ & $74 \pm 8$ & $50 \pm 11$ & $40 \pm 10$ & $29 \pm 9$ & $25 \pm 8$ \\
\hline REM time (min) & $86 \pm 6$ & $73 \pm 6$ & $53 \pm 10$ & $43 \pm 7$ & $34 \pm 9$ & $35 \pm 8$ \\
\hline REM density & $0.98 \pm .08$ & $1.01 \pm .06$ & $.94 \pm .15$ & $.92 \pm .11$ & $.88 \pm .07$ & $.71 \pm .06^{b}$ \\
\hline
\end{tabular}

$\mathrm{EEG}=$ Electroencephalography; REM = rapid eye movement.

All values expressed as mean \pm SEM.

Significance of differences between schizophrenic patients and normal controls:

${ }^{a} p<.01 ;$

${ }^{b} p<.05$;

${ }^{c} p<.10$. 


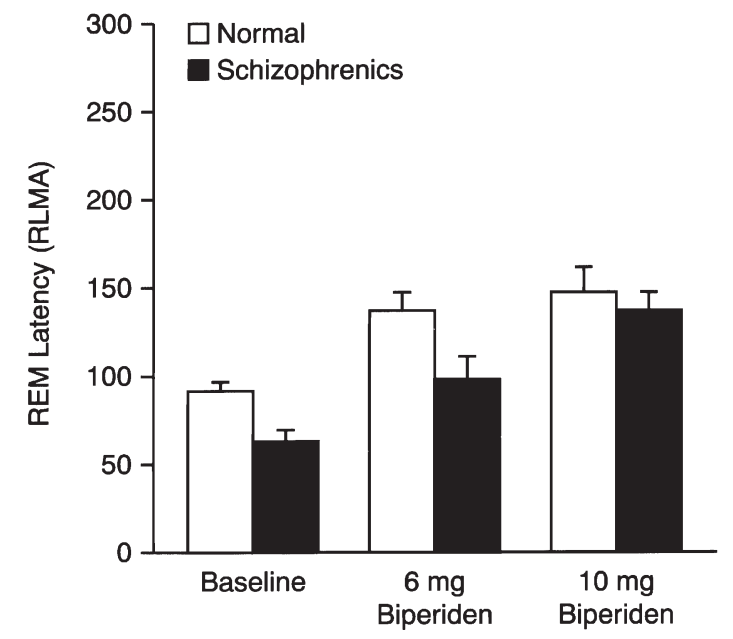

\begin{tabular}{|llrrrc|}
\hline \multicolumn{5}{|c|}{ ANOVA Table for 3-Factor Repeated Measures ANOVA } \\
Source & & Mean \\
Diagnosis & Square & F-test & P value \\
Biperiden dose & (A) & 1 & 20,126 & 5.43 & .0244 \\
Diagnosis by Dose & (AB) & 1 & 2,731 & 0.74 & NS \\
Subjects with groups & & 44 & 22 & 0.01 & NS \\
Repeated measure RLMA & (C) & 1 & 104,705 & - & - \\
Diagnosis by RLMA & (AC) & 1 & 26 & 0.01 & NS \\
Biperiden dose by RLMA & (BC) & 1 & 8,552 & 4.11 & .0312 \\
Diagnosis by dose by RLMA & (ABC) & 1 & 247 & 0.12 & NS \\
C x subjects with group & & 44 & 2,082 & - & - \\
& & & & & \\
\end{tabular}

Figure 2. Effects of two doses of biperiden on REM latency in schizophrenic patients and normal controls.

the presence of increased DA activity. In stabilized patients, DA hyperactivity is presumably corrected, and anticholinergic agents may have no adverse effects on positive symptoms (Goff et al. 1994). Furthermore, because anticholinergic agents are only used in conjunction with neuroleptics in schizophrenia, their direct adverse effects on positive symptoms may be obscured by the direct beneficial effects of DA blockade resulting from concomitant neuroleptic treatment. This might explain why adverse effects of anticholinergics on positive symptoms are not readily apparent in the general clinical setting. In our present study, the effects of biperiden were evaluated in drug-free patients, thereby eliminating the "confounding" effect of neuroleptic medication.

In contrast to the adverse effects of anticholinergic agents on positive symptoms, cholinomimetic agents have transient (somewhat inconsistent) beneficial effects on positive symptoms (Cohen et al. 1944; Collard et al. 1946; Pfeiffer and Jenney 1957). In addition, cholinergic agents may potentiate the effects of neuroleptics in the nucleus accumbens (Vance and Blumberg 1983). These findings are consistent with evidence of a reduction in the severity of positive symptoms that was associated with biperiden withdrawal (and inferred rebound increase in cholinergic activity) in one group of

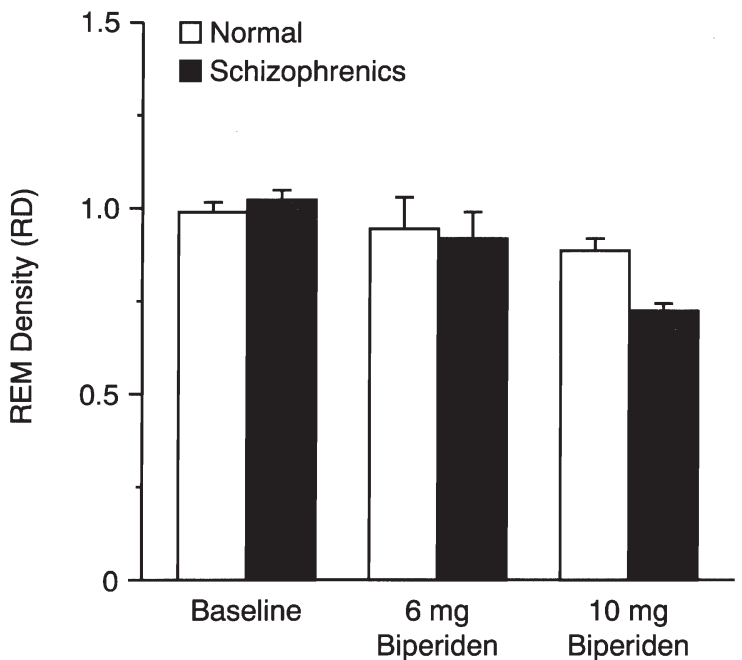

\begin{tabular}{|llrccc|}
\hline \multicolumn{5}{|c|}{ ANOVA Table for 3-Factor Repeated Measures ANOVA } \\
Source & & df & Mean \\
Square & F-test & P value \\
\hline Diagnosis & (A) & 1 & .153 & 1.32 & NS \\
Biperiden dose & (B) & 1 & .099 & 0.85 & NS \\
Diagnosis by Dose & (AB) & 1 & .009 & 0.08 & NS \\
Subjects with groups & & 44 & .116 & - & - \\
Repeated measure RD & (C) & 1 & .914 & 22.84 & .0001 \\
Diagnosis by RD & (AC) & 1 & .162 & 4.05 & .0302 \\
Biperiden dose by RD & (BC) & 1 & .242 & 6.05 & .0179 \\
Diagnosis by dose by RD & (ABC) & 1 & .056 & 1.40 & NS \\
C x subjects with group & & 44 & .04 & - & - \\
\hline
\end{tabular}

Figure 3. Effects of two doses of biperiden on REM density in schizophrenic patients and normal controls.

the first study reported here. Collectively, these data suggest that cholinergic augmentation can play an adjunctive role to neuroleptics in the pharmacological treatment of positive symptoms of schizophrenia. Preliminary data from a study on the augmentation of atypical antipsychotics with donepezil (a cholinesterase inhibitor) in treatment-refractory schizophrenic patients indicated beneficial effects in a proportion of patients (unpublished data). Augmentation with cholinesterase inhibitors, $\mathrm{M}_{1}$ agonists, or partial agonists could prove to be an effective treatment for otherwise neuroleptic-refractory positive symptoms.

Clozapine is an atypical neuroleptic that is effective in treatment-refractory patients (Kane et al. 1988), but its precise mechanism of action is not known. In view of clozapine's potent $\mathrm{M}_{1}$ muscarinic cholinergic activity (Bolden et al. 1991) and its behavior as a partial agonist at the $M_{1}$ receptor in vivo (Ogren 1992; Rivest and Marsden 1991; Meltzer et al. 1994; Zorn et al. 1994; Olianas et al. 1997; Zeng et al. 1997), the cholinergic activity of clozapine has been proposed as one mechanism to explain its superior efficacy in treatment-refractory schizophrenic patients (Tandon and Kane 1993; Tandon 1999). There seems to be a role for muscarinic cholinergic augmentation in the treatment of positive and 


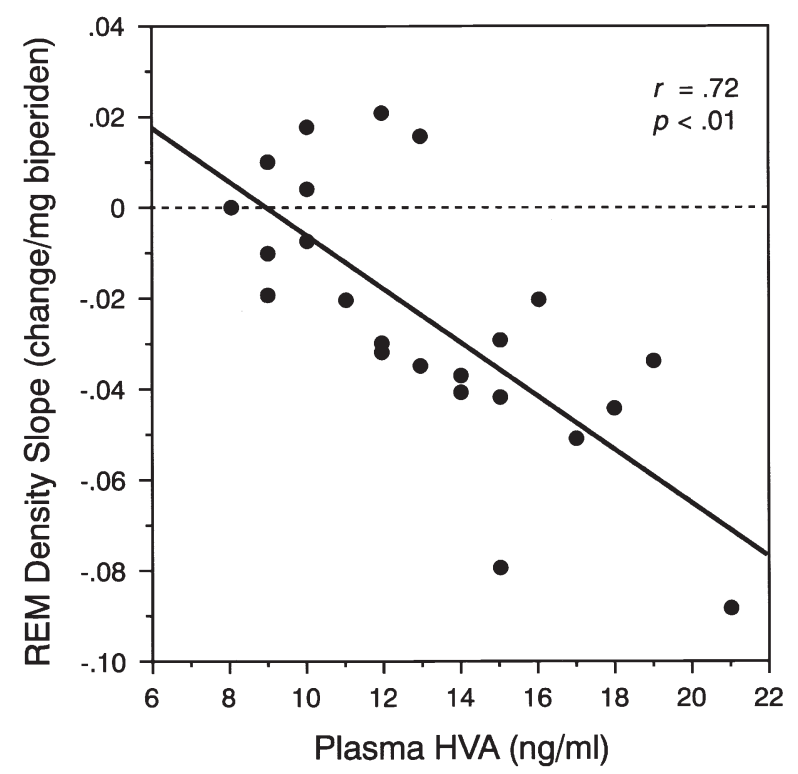

Figure 4. Relationship between change in REM density per mg of biperiden and plasma homovanillic acid (HVA) in schizophrenic patients $(n=24)$.

cognitive symptoms of schizophrenia. Trials to evaluate the efficacy and safety of these treatment strategies in schizophrenia are ongoing.

\section{Polysomnographic Evidence for Increased Cholinergic Activity in Schizophrenia}

Neurotransmitter influences on sleep parameters are complex and interactive; however, advances in understanding the neurobiological mechanisms regulating sleep may permit polysomnography to be used as a strategy to explore the pathophysiology of schizophrenia. Cholinergic mechanisms enhance REM, and increased cholinergic activity results in hyperarousal and impaired sleep continuity, shortened REM latency, and increased REM density (Sitaram and Gillin 1980; Sitaram et al. 1978). In our study, schizophrenic patients exhibited shorter REM latency than normal controls, and both groups showed similar increases in REM latency following biperiden. These data are consistent with the hypothesis of increased cholinergic activity in schizophrenia and with the findings of the two other sleep EEG studies using cholinergic/anticholinergic challenge conducted in schizophrenic patients (Tandon et al. 1991b; Riemann et al. 1994). In a study using a cholinergic challenge paradigm, Riemann and coworkers (Riemann et al. 1994) observed a greater reduction in REM latency and increased number of sleep-onset REM periods (SOREMs) following RS-86 (a relatively specific $\mathrm{M}_{1}$ agonist) (Palacios et al. 1986) in schizophrenic patients than in normal controls. Both of these sets of findings are consistent with the hypothesis of increased cholinergic activity in schizophrenia. Baseline polysom- nographic abnormalities in schizophrenia also indicate increased cholinergic activity in schizophrenia (Tandon et al. 1992b; Gillin et al. 1973).

While sleep findings at drug-free baseline and after cholinergic/anticholinergic modulation are consistent with a hypothesis of increased cholinergic activity in schizophrenia, they are not conclusive. Functional activity of the cholinergic systems involved in sleep regulation may or may not reflect activity of cholinergic systems implicated in schizophrenic pathophysiology. There is, however, an abundant neurobiological substrate for DA-ACh interactions in the brain areas commonly implicated in schizophrenia (Buchsbaum 1990). The hippocampus, nucleus accumbens, septal nuclei, other parts of the limbic system, the dorsolateral prefrontal cortex, and the basal ganglia are richly supplied by septohippocampal, cortical, and other cholinergic pathways (Mesulam et al. 1986). Although there are important DA-ACh interactions in these regions (Damsma et al. 1991; Guo et al. 1992; Moore et al. 1998; Parada et al. 1998), their precise nature is not completely understood.

The model of DA-ACh interactions in schizophrenia (Tandon and Greden 1989) is proposed as a heuristic formulation to understand the neuropharmacological basis of schizophrenic symptoms better, but is not intended as an exhaustive explanation of schizophrenia. Other neurotransmitters are clearly involved, and mechanisms are obviously intertwined. The cholinergic system has been relatively neglected in current theoretical formulations of schizophrenia, despite the fairly large body of data implicating this system in schizophrenic pathophysiology and the fact that anticholinergic agents and neuroleptics with significant anticholinergic activity are routinely employed in the treatment of patients with schizophrenia. This series of studies further implicates the cholinergic system in schizophrenic pathophysiology and sets the stage for further investigations to elucidate the role of cholinergic mechanisms in schizophrenia.

\section{ACKNOWLEDGMENTS}

This work was supported by ADAMHA MH 19634-01 and by grants from the Clinical Research Center (NIH Grant MO1 RR 00042), the National Alliance for Research in Schizophrenia and Affective Disorders (NARSAD), the Scottish Rite Schizophrenia Research Foundation and by an unrestricted educational grant from Hoechst Marion Roussel.

\section{REFERENCES}

American Psychiatric Association (1987): Diagnostic and Statistical Manual of Mental Disorders, 3rd ed., Revised (DSMIII-R). Washington DC: American Psychiatric Association 
Andreasen NC (1983): Scale for the Assessment of Negative Symptoms (SANS). Iowa City: University of Iowa Press

Andreasen NC, Olsen S (1982): Negative v positive schizophrenia: Definition and validation. Arch Gen Psychiat 39:789-794

Angrist B, Rotrosen J, Gershon S (1980): Differential effects of amphetamine and neuroleptics on negative vs. positive symptoms in schizophrenia. Psychopharmacology 72:17-19

Avissar S, Schreiber G (1989): Muscarinic receptor subclassification and G-proteins: Significance for lithium action in affective disorders and for the treatment of the extrapyramidal side-effects of neuroleptics. Biol Psychiat 26:113-130

Berger M, Riemann D, Hochli D, Spiegel R (1989): The cholinergic rapid eye movement sleep induction test with RS-86: State or trait marker of depression? Arch Gen Psychiat 46:421-428

Bolden C, Cusack B, Richelson E (1991): Clozapine is a potent and selective muscarinic antagonist at the five cloned human muscarinic acetylcholine receptors expressed in the CHO-K1 cells. Eur J Pharmacol 192:205-206

Buchsbaum MS (1990): The frontal lobes, basal ganglia, and temporal lobes as sites for schizophrenia. Schizophr Bull 16:379-389

Carlsson M, Carlsson A (1990): Interactions between glutamatergic and monoaminergic systems within the basal ganglia-Implications for schizophrenia and Parkinson's disease. TINS 13:272-276

Carroll BJ, Greden JF, Haskett RF, Feinberg M, Albala AA, Martin FIR, Rubin RT, Heath B, Sharp PT, McLeod WL, McLeod MF (1980): Neurotransmitter studies of neuroendocrine pathology in depression. Acta Psychiat Scand Suppl 61:183-199

Chouinard G, Annable L, Mercier P, Turnier L (1987): Longterm effects of L-dopa and procyclidine on neurolepticinduced extrapyramidal and schizophrenic symptoms. Psychopharmacol Bull 23:221-226

Cohen LH, Thale T, Tissenbaum MJ (1944): Acetylcholine treatment of schizophrenia. Arch Neurol Psychiat 51:171-175

Collard J, Lecoq R, Demaret A (1946): Un essai de therapeutique pathogenique de la schizophrenei par un acetylcholinique: l'oxotremorine. Acta Neurological et Psychiatrica Belgica 65:122-127

Crow TJ (1980): Molecular pathology of schizophrenia: More than one disease process? Br Med J 280:66-68

Damsma G, Robertson GS, Tham CS, Fibiger HC (1991): Dopaminergic regulation of striatal acetylcholine release: Importance of D1 and N-methyl-D-aspartate receptors. J Pharmacol Exp Ther 259:1064-1072

Davila R, Manero E, Zumarraga M, Andia I, Schweitzer JW, Friedhoff AJ (1988): Plasma homovanillic acid as a predictor of response to neuroleptics. Arch Gen Psychiat 45:564-567

Davis KL, Berger PA (1978): Pharmacological investigations of the cholinergic imbalance hypotheses of movement disorders and psychosis. Biol Psychiat 13:23-49

Davis KL, Hollister LE, Berger PA, Barchas JD (1975): Cholin- ergic imbalance hypotheses of psychoses and movement disorders: Strategies for evaluation. Psychopharmacol Commun 1:533-543

Davis KL, Hollister LE, Overall J, Johnson A, Train K (1976): Physostigmine: Effects on cognition and affect in normal subjects. Psychopharmacology 51:23-27

Docherty JP, van Kammen DP, Siris SG, Marder SR (1978): Stages of onset of schizophrenic psychosis. Am J Psychiat 135:420-426

Donlon P, Blacker K (1973): Stages of schizophrenic decompensation and reintegration. J Nerv Ment Dis 157:200209

Douglass A, Bornstein R, Nino-Murcia G, Keenan S, Miles L, Zarcone V, Guilleminault C, Dement W (1986): Creation of the ASDC sleep disorders questionnaire. Sleep Res $15: 117$

Eltze M, Figala V (1988): Affinity and selectivity of biperiden enantiomers for muscarinic receptor subtypes. Eur J Pharmacol 158:11-19

Endicott J, Spitzer RL (1978): A diagnostic interview: The schedule for affective disorders and schizophrenia. Arch Gen Psychiat 35:837-844

Fayen M, Goldman MB, Moulthrop MA, Luchins DJ (1988): Differential memory function with dopaminergic versus anticholinergic treatment of drug-induced extrapyramidal symptoms. Am J Psychiat 145:483-486

Fisch RZ (1987): Trihexyphenidyl abuse: Therapeutic implications for negative symptoms of schizophrenia. Acta Psychiat Scand 75:91-94

Friedhoff AJ, Alpert M (1973): A dopaminergic-cholinergic mechanism in production of psychotic symptoms. Biol Psychiat 6:165-169

Gerlach J, Rasmussen PT, Hansen L, Kristjansen P (1977): Antiparkinsonian agents and long-term neuroleptic treatment: Effect of G 31.406, orphenadrine, and placebo on parkinsonism, schizophrenic symptoms, depression, and anxiety. Acta Psychiat Scand 55:251-260

Gillin JC, Sitaram N (1984): Rapid eye movement (REM) sleep: Cholinergic mechanisms. Psychol Med 14:501506

Gillin JC, Post RM, Wyatt RJ, Goodwin FK, Snyder F, Bunney WE (1973): REM inhibitory effect of L-dopa infusion during human sleep. Electroenceph Clin Neurophysiol 35:181-186

Gillin JC, Sitaram N, Mendelson WB, Wyatt RJ (1978): Physostigmine alters onset but not duration of REM sleep in man. Psychopharmacology 58:111-114

Gillin JC, Sutton L, Ruiz C, Golshan S, Hirsch S, Warman C, Shiromani PJ (1991): Dose-dependent inhibition of REM sleep in normal volunteers by biperiden, a muscarinic antagonist. Biol Psychiat 30:151-156

Goff DC, Amico E, Dreyfuss D, Ciraulo D (1994): A placebocontrolled trial of trihexyphenidyl in unmedicated patients with schizophrenia. Am J Psychiat 151:429-431

Grimaldi R, Perucca E, Ruberto G, Gelmi C, Trimarchi F, Hollmann M, Crema A (1986): Pharmacokinetic and pharmacodynamic differences following the intravenous and oral administration of the antiparkinson drug biperiden to normal subjects. Eur J Clin Pharmacol 29:735-737 
Guo N, Robertson GS, Fibiger HC (1992): Scopolamine attenuates haloperidol-induced c-fos expression in the striatum. Brain Res 588:164-167

Guy W (1976): ECDEU Assessment Manual for Psychopharmacology, (DHEW Publication No. 76-338), National Institute of Mental Health, Rockville, MD

Haase H-J (1965): The relationship of neuroleptic action to extrapyramidal phenomena. In Haase H-J, Janssen PAJ (eds), The Action of Neuroleptic Drugs. Amsterdam: North Holland Publishing Company, pp 56-103

Hedlund JL, Vieweg BW (1980): The Brief Psychiatric Rating Scale (BPRS): A comprehensive review. J Operational Psychiat 11:48-65

Hollmann M, Brode E, Greger G, Muller-Peltzer H, Wetzelsberger N (1984): Biperiden effects and plasma levels in volunteers. Eur J Clin Pharmacol 27:619-621

Horn AS, Coyle JT, Snyder SH (1971): Catecholamine uptake by synaptosomes from rat brain. Structure-activity relationships of drugs with differential effects on dopamine and norepinephrine neurons. Mol Pharmacol 7:66-80

Janowsky DS, El-Yousef MK, Davis JM, Sekerke HJ (1972): A cholinergic-adrenergic hypothesis of mania and depression. Lancet 2:632-635

Janowsky DS, El-Yousef MK, Davis JM, Sekerke HJ (1973): Antagonistic effects of physostigmine and methylphenidate in man. Am J Psychiat 130:1370-1376

Janowsky DS, Risch SC, Kennedy B, Ziegler M, Huey L (1986): Central muscarinic effects on mood, cardiovascular function, pituitary and adrenal neuroendocrine release. Psychopharmacology 89:150-154

Jibson MO, Tandon R (1998): New atypical antipsychotic medications. J Psychiat Res 32:215-228

Johnstone EC, Crow TJ, Ferrier IN, Frith CD, Owens DGC, Bourne RC, Gamble SJ (1983): Adverse effects of anticholinergic medication on positive schizophrenic symptoms. Psycholog Med 13:513-527

Johnstone EC, Crow TJ, Frith CD, Owens DG (1988): The Northwick Park "functional" psychosis study: Diagnosis and treatment response. Lancet 2:119-125

Kane JM, Honigfeld G, Singer J, Meltzer HY (1988): Clozapine for the treatment-resistant schizophrenic: A double-blind comparison with chlorpromazine. Arch Gen Psychiat 45:789-796

Maixner S, Tandon R, Douglass A, Shipley JE, Decker L, Goldman M (1996): Polysomnographic abnormalities in schizophrenia: A replication. Biol Psychiat 39:552-553

Maixner S, Tandon R, Eiser A, Taylor SF, DeQuardo JR, Shipley J (1998): Effects of antipsychotic treatment on polysomnographic measures in schizophrenia: A replication and extension. Am J Psychiat 155:1600-1602

Manos N, Gkiouzepas J, Tzotzoras T, Tzanetoglou A (1981): Gradual withdrawal of antiparkinson medication in schizophrenics: Any better than the abrupt? J Nerv Ment Dis 169:659-661

Meltzer HY (1989): Clinical studies on the mechanism of action of clozapine: The dopamine-serotonin hypothesis of schizophrenia. Psychopharmacology 99 Suppl:S18-27

Meltzer HY, Chai BL, Thompson PA, Yamamoto BK (1994): Effect of scopolamine on the efflux of dopamine and its metabolites after clozapine, haloperidol or thioridazine. J Pharm Exp Ther 268:1452-1461

Mesulam M-M, Volicer L, Marquis JK, Mufson EJ, Green RC (1986): Systematic regional differences in the cholinergic innervation of the primate cerebral cortex: Distribution of enzyme activities and some behavioral implications. Ann Neurol 19:144-151

Modell JG, Tandon R, Beresford T (1989): Dopaminergic activity of the "antimuscarinic" antiparkinsonian agents. J Clin Psychopharmacol 9:347-351

Modestin J, Schwartz RB, Hunger J (1973): Zur frage beeinflussung schizophrener symptome durch physostigmin. Pharmakopsychiatr Neuropsychopharmakol 6:300-304

Moore H, Fadel J, Sarter M, Bruno JP (1998): Role of accumbens and cortical dopamine receptors in the regulation of cortical acetylcholine release. Neuroscience 58:811-822

Ogren SO (1992): Pharmacology of atypical neuroleptic drugs: Relevance for muscarinic mechanisms in schizophrenia. Scientific Proceedings of the American College of Neuropsychopharmacology Annual Meeting, San Juan, Puerto Rico

Olianas MC, Maullu C, Onali P (1997): Effects of clozapine on rat striatal muscarinic receptors coupled to inhibition of adenylyl cyclase activity and on the human cloned $\mathrm{m} 4$ receptor. Br J Pharmacol 122:401-408

Overall JE, Gorham DR (1962): The Brief Psychiatric Rating Scale. Psycholog Rept 10:799-812

Palacios JM, Bolliger G, Closse A, Enz A, Gmelin G, Malanowski J (1986): The pharmacological assessment of RS 86 (2-ethyl-8-methyl-2,8-diazaspiro-[4,5]-decan-1,3-dion hydrobromide): A potent, specific muscarinic acetylcholine receptor agonist. Eur J Pharmacol 125:45-62

Parada MA, Parada MPD, Hernandez L, Garcia F, Murzi E, Conperas Q (1998): Clozapine-induced acetylcholine release in the rat prefrontal cortex, nucleus accumbens, and striatum does not develop tolerance. Prog NeuroPsychopharmacol Biol Psychiat 22:1379-1397

Pfeiffer CC, Jenney EH (1957): Inhibition of the conditioned response and the counteraction of schizophrenia by muscarinic stimulation of the brain. Ann NY Acad Sci 66:753-764

Pickar D, Breier A, Hsiao JK, Doran AR, Wolkowitz OM, Pato CN, Konicki PE, Potter WZ (1990): Cerebrospinal fluid and plasma monoamine metabolites and their relation to psychosis: Implications for regional brain dysfunction in schizophrenia. Arch Gen Psychiat 47:641-648

Poland RE, McCracken JT, Lutchmansingh P, Lesser IM, Tondo L, Edwards C, Boone KB, Lin K-M (1997): Differential response of rapid eye movement sleep to cholinergic blockade by scopolamine in currently depressed, remitted, and normal control subjects. Biol Psychiat 41:929-938

Rechtschaffen A, Kales A, Berger RJ (1968): A Manual of Standardized Terminology, Techniques, and Scoring System for Sleep Stages in Human Subjects. Public Health Service, U.S. Government Printing Office, Washington DC

Richelson E (1984): Neuroleptic affinities for human brain receptors and their use in predicting adverse effects. J Clin Psychiat 45:331-336 
Riemann D, Gann H, Fleckenstein P, Hohagen F, Olbrich R, Berger M (1994): Effect of RS 86 on REM latency in schizophrenia. Psychiat Res 38:89-92

Rifkin A, Quitkin F, Kane J, Struve F, Klein DF (1978): Are prophylactic antiparkinson drugs necessary? A controlled study of procyclidine withdrawal. Arch Gen Psychiat 35:483-489

Risch SC, Cohen RM, Janowsky DS, Kalin NH, Sitaram N, Gillin JC, Murphy DL (1981): Physostigmine induction of depressive symptomatology in normal human subjects. Psychiat Res 4:89-94.

Rivest R, Marsden CA (1991): Inhibition of apomorphineinduced climbing in mice by cholinergic drugs and clozapine. Br J Pharmacol 104:234-238

Rowntree DW, Nevin S, Wilson A (1950): The effects of diisopropylfluorophosphonate in schizophrenia and manic depressive psychosis. J Neurol Neurosurg Psychiat 13:47-62

Salin-Pascual RJ, Granados-Fuentes D, Galicia-Polo L, Nieves E (1991): Rapid eye movement (REM) sleep increases by auditory stimulation reverted with biperiden administration in normal volunteers. Neuropsychopharmacology 5:183-186

Sandyk R, Kay SR (1990): The relationship of negative schizophrenia to parkinsonism. Int J Neurosci 55:1-59

Schuberth J, Jenden DJ (1975): Transport of choline from plasma to cerebrospinal fluid in the rabbit with reference to the origin of choline and to acetylcholine metabolism in brain. Brain Res 84:245-256

Singh MM, Kay SR (1979): Therapeutic antagonism between anticholinergic antiparkinsonism agents and neuroleptics in schizophrenia: Implications for a neuropharmacological model. Neuropsychobiology 5:74-86

Singh MM, Kay SR. Opler LA (1987): Anticholinergic-neuroleptic antagonism in terms of positive and negative symptoms of schizophrenia: Implications for psychobiological subtyping. Psycholog Med 17:39-48

Sitaram N, Gillin JC (1980): Development and use of pharmacological probes of the CNS in man: Evidence of cholinergic abnormality in primary affective illness. Biol Psychiat 15:925-955

Sitaram N, Moore AM, Gillin JC (1978): Experimental acceleration and slowing of REM sleep ultradian rhythm by cholinergic agonist and antagonist. Nature 274:490-492

Spitzer RL, Endicott J (1979): Schedule for Affective Disorders and Schizophrenia-Lifetime Version (SADS-L), 3rd ed. New York: New York State Psychiatric Institute

Spitzer RL, Endicott J, Robins E (1978): Research Diagnostic Criteria (RDC): Rationale and reliability. Arch Gen Psychiat 35:773-782

Sumiyoshi T, Hasegawa M, Jayathilake K, Meltzer HY (1997): Prediction of short-term changes in symptom severity by baseline plasma homovanillic acid levels in schizophrenic patients receiving clozapine. Psychiat Res 69:113-121

Syvalahti EKG, Lauren L, Markannen J, Kunelius R (1987): Interaction of psychotropic drugs with brain muscarinic cholinoceptors: Similarities of biperiden with pirenzipine in receptor binding properties. Pharmacol Toxicol 60:66-69
Tandon R (1997): Effects of atypical antipsychotics on polysomnographic measures in schizophrenia. Bibliog Psychiat 167:219-222

Tandon R (1999): Cholinergic aspects of schizophrenia. Br J Psychiat Suppl 173:7-11

Tandon R, Greden JF (1989): Cholinergic hyperactivity and negative schizophrenic symptoms: A model of dopaminergic/cholinergic interactions in schizophrenia. Arch Gen Psychiat 46:745-753

Tandon R, Greden JF (1991): Cholinergic excess and the negative schizophrenic syndrome. In Greden JF, Tandon R (eds), Negative Schizophrenic Symptoms: Pathophysiology and Clinical Implications. Washington DC: American Psychiatric Press, pp 99-111

Tandon R, Kane JM (1993): Neuropharmacologic basis for clozapine's unique profile. Arch Gen Psychiat 50:157159

Tandon R, Greden JF, Silk KR (1988): Treatment of negative schizophrenic symptoms with trihexyphenidyl. J Clin Psychopharmacol 8:212-215

Tandon R, Goldman R, Goodson J, Greden JF (1990a): Mutability and relationship between positive and negative symptoms during neuroleptic treatment in schizophrenia. Biol Psychiat 27:1323-1326

Tandon R, Mann N, Eisner W, Coppard N (1990b): Effect of anticholinergic medication on positive and negative symptoms in medication-free schizophrenic patients. Psychiat Res 31:235-241

Tandon R, Mazzara C, DeQuardo J, Craig KA, Meador-Woodruff JH, Goldman R, Greden JF (1991a): Dexamethasone suppression test in schizophrenia: Relationship to symptomatology, ventricular enlargement, and outcome. Biol Psychiat 29:953-964

Tandon R, Greden JF, Goodson J, Shipley JE, Mann N, Eisner W (1991b): Muscarinic cholinergic hyperactivity in schizophrenia: Relationship to positive and negative symptoms. Schizoph Res 4:23-30

Tandon R, DeQuardo JR, Goodson J, Mann NA, Greden JF (1992a): Effect of anticholinergics on positive and negative symptoms in schizophrenia. Psychopharm Bull 28:297-302

Tandon R, Shipley JE, Taylor S, Greden JF, Eiser A, DeQuardo JR, Goodson J (1992b): Electroencephalographic sleep abnormalities in schizophrenia: Relationship to positive/negative symptoms and prior neuroleptic treatment. Arch Gen Psychiat 49:185-194

Tandon R, Greden JF, Haskett RF (1993): Cholinergic hyperactivity and negative symptoms: Behavioral effects of physostigmine in normal controls. Schizophr Res 9:19-23

Tandon R, Lewis C, Taylor SF, Shipley JE, DeQuardo JR, Jibson M, Goldman M (1996): Relationship between DST nonsuppression and shortened REM latency in schizophrenia. Biol Psychiat 40:660-663

Taylor SF, Tandon R, Shipley JE, Eiser AS (1991): Effect of neuroleptic treatment on polysomnographic measures in schizophrenia. Biol Psychiat 30:904-912

van Kammen DP, Peters J, Yao J, van Kammen WB, Neylan T, Shaw D, Linnoila M (1990): Norepinephrine in acute exacerbations of chronic schizophrenia: Negative symptoms revisited. Arch Gen Psychiat 47:161-168 
Vance MA, Blumberg JB (1983): Cholinergic potentiation of neuroleptic effects in the nucleus accumbens. Res Commun Chem Pathol Pharmacol 40:345-348

Wells BG, Marken PA, Rickman LA, Brown CS, Hamann G, Grimmig J (1989): Characterizing anticholinergic abuse in community mental health. J Clin Psychopharmacol 9:431-435
Zeng XP, Le F, Richelson E (1997): Muscarinic m4 receptor activation by some atypical antipsychotic drugs. Eur J Pharmacol 321:349-354

Zorn SH, Jones SB, Ward KM, Liston DR (1994): Clozapine is a potent and selective muscarinic M4 receptor agonist. Eur J Pharmacol 269:R1-2 